\title{
Prolonged Response Times in Obstetric Emergency Care Out of Hospital in Yucatan, Mexico
}

\author{
Elsa María Rodríguez Angulo*, Yolanda Oliva Peña, Ricardo Ojeda Rodríguez and María \\ Guadalupe Andueza Pech \\ Social Medicine Laboratory, Center of Regional Researches "Dr. Hideyo Noguchi”. Autonomous University of Yucatan, Mexico
}

\begin{abstract}
Background: Shortening the response time in obstetric emergency care helps reduce deaths. The length of response times in the care so as the probabilities these times are occurring, are unknown in Yucatan, Mexico. This study describes the perceptions and beliefs of physicians regarding response times in the care of obstetric emergencies, so as the probabilities that these times are occurring.
\end{abstract}

Methods: Cross-sectional design was carried out. Workshops using elicitation technique with panel of experts were developed. Four physicians in charge of the path transfer of pregnant women were the participants. Physicians' perceptions and beliefs on response times in the path care of obstetric emergencies were studied using "The threedelay model". Probabilities of these response times occurring was calculated. The median and their ranges were obtained. Probability diagrams were elaborated and adjusted to know the median occurrence of response times. Normal distribution curve was also graphed. Beta adjusted distribution lineal graph individual and group was built.

Results: The longest response time perceived between the onset of the obstetric complication and the search for help was 30 days. The longest transfer response time perceived between their locality and the hospital was four and a half hours. The probabilities of the perceived response times occurring were between 15\% and 80\% for the moment the women start searching for help; and between $40 \%$ and $80 \%$ for the moment they are transferred.

Conclusion: Response times perceived by physicians in the care of obstetric emergencies in Yucatan were prolonged. The probability of these response times been occurring is high. It is necessary to strengthen activities of health promotion in the first level of care. The transfer system of pregnant women should also be enhanced, so the delays in the response times are reduced and maternal and perinatal deaths prevented in Yucatan.

KEYWORDS: Response times probabilities; Obstetric emergency

ABBREVIATIONS: OEs: Obstetric Emergencies; EmOC: Emergency Obstetric Care; BA: Born Alive; J1: Jurisdiction \#1; J2: Jurisdiction \#2; J3: Jurisdiction \#3.

Quick Response Code:

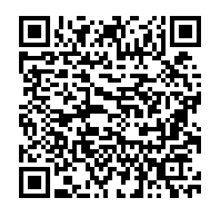

Address for correspondence: Elsa María Rodríguez Angulo, Social Medicine Laboratory. Center of Regional Researches "Dr. Hideyo Noguchi". Autonomous University of Yucatan, Mexico

Received: April 20, 2020 Published: April 29, 2020

How to cite this article: Elsa MRA, Yolanda OP, Ricardo OR, María GAP. Prolonged Response Times in Obstetric Emergency Care Out of Hospital in Yucatan, Mexico. 2020 - 2(2) OAJBS. ID.000167. DOI: $10.38125 / O A J B S .000167$ 


\section{INTRODUCTION}

Timely care of obstetric emergencies (OEs) is a challenge that the health systems of developing countries are still facing [1]. According to the World Health Organization, 810 women die daily due to complications that are OEs [2]. In developed countries, the risk of women dying during pregnancy is 1 in 3 800, whereas in Sub-Saharan countries it is 1 in 39 [3,4]. Most obstetric deaths are preventable if alarm signs pointing to a complication are detected in time and women are transferred in time to clinics or hospitals with specialized resources to treat the emergency. When access to services is limited, the risk of early deaths increases [5].

An $\mathrm{OE}$ is a condition in the mother's health state that endangers her life and/or that of the fetus and requires immediate care [6]. Studies carried out to find out the clinical causes of OEs have determined that preeclampsia/eclampsia, hemorrhage, sepsis, miscarriage and obstructed labor are the main complications requiring emergency medical and/or surgical care [7-9]. A key strategy to prevent death is the reduction of comprehensive emergency obstetric care (EmOC) and newborn care response times [10]. This consists of a set of interventions that save lives in most cases of maternal and newborn morbidity and mortality due to an obstetric emergency, since they provide, at least, basic emergency treatment at the first level care facilities in the health system of a country [6]. It has been estimated that the average time for death to occur since the onset of an $\mathrm{OE}$ is two hours in the case of postpartum hemorrhage, two days in the case of eclampsia and obstructed labor, and six days in the case of an infectious process [2].

Poor quality of care in the treatment of OEs leads to maternal deaths [5]. Up to the 14 weeks of 2020, a maternal mortality rate of 22.3 per 100000 born alive (BA) was reported in the state of Yucatan; this figure is below the national mean of 27.4 per 100000 BA [11]. Women living far away from hospitals are the ones with a higher risk of death due to delays in care; so are their unborn babies.

With Thaddeus and Maine's 1994 delay model [12] as a reference framework, it has been possible to study community barriers causing delays in Yucatan. Women and their families face these barriers from the onset of the complication up to their arrival to the hospital where they are referred for treatment of the emergency. The first delay has to do with the prolonged time the pregnant woman takes to seek for care, from the onset of the complication to the moment of leaving her house. The second delay comprises the prolonged time from the moment when the woman leaves her home to seek for help until the moment when she reaches the health center, she is transferred, and she arrives at a hospital. The third delay is the prolonged waiting time when reaching the hospital; it also has to do with diagnostic and treatment errors. The main barriers that have been found at a community level are the failure to recognize the alarm signs of a complication and the lack of availability of a means of transportation to the hospital $[13,14]$.

Although there is a vast literature showing that maternal mortality is very sensitive to the care standards of the $\mathrm{OE}$, the differences in the levels of maternal mortality between low-income and high-income countries are usually due to the differences in the interval between the onset of the first symptom and the time when it is managed or controlled [15-17]. Among the factors that prolong the response times, the following have been identified: the failure to recognize the complication, the women's reluctance to be treated at a hospital, the cost of being referred to another hospital, the delays in the transfer, and the poor quality of hospital care [17]. It is essential to know and shorten these time intervals to identify opportunities to improve pregnant women and their families' search for help by reducing times of exposure to risk due to delays. Preliminary reports of the relatives of women who had home deliveries, underwent a complication and died in Yucatan, point to prolonged response times of up to two hours from the moment when they started seeking help until they got it. Even in those deliveries treated at clinics or hospitals, response times ranged from one to two hours. In the cases of deliveries complicated by hemorrhage, the time between the onset of the first symptom and the provision of care ranged between one and two hours. The lapse was five hours long in the case of eclampsia, and between three and five days in the case of sepsis [18].

Studies carried out in Yucatan on the care of OEs have referred that there are clinical, sociocultural and administrative aspects that limit the performance of a model to prevent delays in the care of pregnant women with obstetric complications [19]. However, the physicians' beliefs on the response times and the probabilities of delays occurring are yet unknown. In this study, the principal aim was to describe the physicians' perceptions and beliefs, calculate how likely they are occurring, regarding the response times for the treatment of obstetric complications in Yucatan, Mexico. This knowledge will allow propose strategies that reduce prolonged response times in the care of an obstetric emergency at a community level (first and second delays).

\section{METHODS}

\section{Study Design, Duration and Settings}

A cross-sectional retrospective observational study was designed, and it was carried out by means of an elicitation technique with a panel of experts [20]. The technique allowed to extract the physicians' a priori knowledge (perceptions and beliefs) on the time interval perceived in the care of pregnant women with obstetric emergency, and the probabilities of these times perceived were occurring. Although care of the obstetric emergency must be immediate [21], for the purpose of this study, time interval of response of more than an hour between the onset of the symptoms and to arrive to the hospital was considered prolonged (delay).

Four workshops were carried out to analyze under "The three delays model", the transfer pathways of pregnant women with obstetric emergency. During the sessions, the physicians were asked to reflect on the time interval perceived between the onset of the symptoms and the search of medical care (first delay); and on the time interval between the transferal notice, be transferred, and to arrive to the clinic or hospital where the woman was transferred (second delay). Each one of the physicians mentioned a time interval accord to case. All time intervals perceived were commented among physicians until a consensus was reached. After of that, probabilities of that these times were occurring were calculated. A facilitator trained in the probability elicitation technique, served as guide to the physicians' group during the sessions. The process of elicitation was carried out following the method described by Gartawaite, Kadane and O'Hagan [22], which was adapted for the purposes of this study and it consisted in 10 stages: 1 . Presentation of the researchers; 2 . Personal characteristics from the physician; 3. Simulation exercise of probabilities; 4 . Definition of what researchers to wish to know; 5. Evidence on which the physicians' knowledge is based; 6. Median range calculation; 7. Median estimate; 8. Probability estimation; 9. Feedback 10. Final probabilities obtained. 
The study was performed in the State of Yucatan, in Southeast of Mexico. In terms of health coverage, the 106 municipalities that conforming are distributed in three Sanitary Jurisdictions, each of which has a definite number of municipalities assigned for health care. Jurisdiction \#1 (J1), located in the North-central area includes 61 municipalities; Jurisdiction \#2 (J2), located in the eastern area includes 24, and Jurisdiction \#3 (J3), located in the South of the State includes 21 municipalities. Health Centers at every municipality send the pregnant women to a clinic or a hospital out of the locality, to treat the OE. Each Jurisdiction has physicians in charge of monitoring the route or pathway that women follow when they suffer from an obstetric complication and are transferred from Health Center to the hospital. Physicians in charge of monitoring are in permanent touch with physicians at the Health Centers, which are the women's first contact when an obstetric complication first arises.

\section{Participants, Sample Size and Recruitment Criteria}

The participants in this study were four jurisdictional physicians in charge of monitoring to the pregnant women when they leave home to search care and are transferred to another health facility. Jurisdictional physicians know the routes that are followed by the cases of $\mathrm{OE}$ in the three Sanitary Jurisdictions from the Ministry of Health in Yucatan. From a universe of twenty physicians distributed in the three Jurisdictions, a simple random size was calculated, with the support of the software Epi-Info vs. 7; with an acceptable margin of error of $6 \%$ and a confidence level of $95 \%$, four physicians made up the simple. These represented to the twenty physicians distributed in the three Sanitary Jurisdictions, in charge of monitoring to the pregnant women with OE.

The inclusion criteria to select the four physicians were: 1 .To have had at least five years of experience and knowledge of the transfer pathways of pregnant women with obstetric complications; 2. To be currently working in the Sanitary Jurisdictions in Yucatan; and 3. they had to be familiar with the path that the pregnant woman follows since the onset of the first symptom of obstetric complication, the moment she seeks for help, and her arrival to the hospital. Other issues were also taken into account: their willingness to engage in service improvement, their time to freely address the topics given the confidentiality condition, their process of reflection and analysis of their perceptions and beliefs on the response times required by pregnant women seeking emergency care, and their knowledge of probability and statistics. Of twenty doctors working in the Sanitary Jurisdictions in Yucatan, ten met eligibility criteria and ten did not. Of the latter, two was due to lack of time, four had less than five years of service, three were not sure of the route of pregnant woman's and one was outdated. Of the ten doctors who met the criteria, four were randomly selected and represented the three Sanitary Jurisdictions. An invitation was extended, first by telephone and then in writing, to the directors of the three Sanitary Jurisdictions. The four physicians, who met the inclusion criteria and had been previously selected, answered the call.

\section{Delays Model}

To analyze the time intervals invested in seeking for help (first delay) and in the transfer process (second delay), Thaddeus y Maine's [14] delays model was used as a basis. To be more accurate regarding the data, the first delay was subdivided in two: Delay 1a referred to the time elapsed between the onset of the complication and the moment the pregnant woman became aware of it. Delay $1 \mathrm{~b}$ referred to the time elapsed between the moment the woman became aware of the complication and the moment when she decided to look for help. The second delay was also subdivided in two: Delay 2a referred to the time elapsed between the moment the pregnant women left her home seeking for help and the moment she arrived to a health center. Delay $2 \mathrm{~b}$ referred to the time elapsed between the moment the woman was taken care of at the Health Center and the moment she was transferred to a hospital for final treatment.

\section{Instrument and Elicitation of Probabilities}

Using an elicitation technique with a panel of experts, the physicians' perceptions and beliefs were extracted. Before the elicitation process, a simulation exercise of probabilities was carried out. The physicians answered a question with which they were able to practice the process of reflecting on probabilities, similar to the one conducted at the final elicitation. This exercise also helped to identify doubts that were therein cleared up. Afterwards, physicians engaged in the final elicitation of probabilities. In order to be able to elicit the physicians' perceptions and beliefs on the response time intervals in the care of pregnant women with OEs, a questionnaire adapted to the scenarios of the first and second delays was elaborated. Each physician selected signed a voluntary consent to participate in the study.

Initially, the physicians were asked to think about the response time intervals perceived in terms of minutes, hours or days. Through the elicitation process, the response times regarding the first ( $1 \mathrm{a}$ and $1 \mathrm{~b}$ ) and the second delays ( $2 \mathrm{a}$ and $2 \mathrm{~b}$ ) were identified independently. The questions to elicit the perceptions and beliefs regarding the first delay were as follows: According to your experience, how long do you think pregnant women take to look for help since the onset of the complication until they become aware of it? (1a), and How long do you think pregnant women with an obstetric complication take to decide to look for help since they realize that they have a complication until they actually go out looking for help? (1b).

For the perceptions and beliefs regarding the second delay, the questions were as follows: How long do you think pregnant women with an obstetric complication take to find help since they leave their home looking for it until they get hold of a vehicle that will transfer them to another facility? (2a), and How long do you think pregnant women with an obstetric complication take to arrive to another medical facility after getting hold of a transfer vehicle? (2b).

In this way, time intervals perceived of response regarding the care of pregnant women -in days, hours and minutes-were obtained, after of which, the probabilities that those times were occurring were calculated. To facility the physicians' analysis to identify the probability of occurrence of the times elapsed, $1 \mathrm{a}$ and $1 \mathrm{~b}$ were resumed in one, and the same was done with $2 \mathrm{a}$ and $2 \mathrm{~b}$. Then, the following questions were posed: What is the probability that the time you have mentioned, between the onset of the complication and the moment the pregnant woman leaves her home, looks for help and gets hold of transportation for the transfer (first delay), occur?, and What is the probability that the times you have mentioned, between the transfer of a pregnant woman with obstetric complication, since she gets hold of a vehicle until she arrives to the hospital (second delay), occur?

The probabilities calculated were the median and their ranges. First, each physician was asked to provide a range of values (upper and lower limits of the interval between 0-1) in which, the probability of response time perceived could be occurring, during the process of search for women's care front an OE. After that, a probability within that range (not necessarily the middle one), in which the time perceive would be occurring (median), 
was requested. Therefore, for each stage in the process of search for care, a range of values, including the median, was requested. Taking into consideration the possibility of inaccuracy in the data, the physicians were asked again to think how much lower and how much higher than the middle value, the new values could now be. In this way, by consensus, the distribution of data was adjusted. At the end of the process and following "The Three delay model", probabilities of occurring times perceived (median and their ranges) for the first and second delays, were obtained.
Using software Shelf version 2.0 [23], distribution graphs of the physicians' individual probabilities were built, and they were shared during the sessions to know if they agreed with the figures. When they were not in agreement, the process was carried out again, until the physician agreed with the best distribution of probabilities. Normal distribution curve was also graphed. Finally, when each participant's probabilities were agreed on, a Beta adjusted distribution lineal graph individual and group was built.

\section{RESULTS}

Table 1: Characteristics of physician's participants.

\begin{tabular}{|c|c|c|c|c|c|}
\hline Number & Age & Sex & Job site & Years of service & Probability and statistics \\
\hline 1 & 65 & M & Jurisdiction 1 & 10 & Yes \\
\hline 2 & 43 & M & Jurisdiction 3 & 7 & Yes \\
\hline 3 & 64 & M & Jurisdiction 2 & 15 & Yes \\
\hline 4 & 58 & M & Jurisdiction 2 & 12 & Yes \\
\hline
\end{tabular}

The four participant physicians in the elicitation process were male: one from J1, one from J3, and two from J2. Their age range was 40 to 65 years, with a mean of 57.4 (Table 1). The longest delay time perceived between the onset of the complication and the search for help (delay 1a) was 30 days, and it corresponded to the women from the J1 municipalities. The longest transfer delay perceived, from their locality to the referral hospital (delay 2b), was 2 hours and 45 minutes for pregnant women from the $\mathrm{J} 2$ municipalities (Table 2). The probability of occurring the longest total delay times perceived also corresponded to J1 and J2.

Table 2: Response times perceived by the physicians according to the type of delay in pregnant women with OEs.

\begin{tabular}{|c|c|c|c|c|}
\hline Physician & Delay 1a & Delay 1b & Delay 2a & Delay 2b \\
\hline $1(J 1)$ & 30 days & 15 hours & 1 hour and 30 minutes & 1 hour and 30 minutes \\
\hline $2(\mathrm{~J} 3)$ & 2 hours & 2 hours and 30 minutes & 1 hour and 30 minutes & 50 minutes \\
\hline $3(\mathrm{~J} 2)$ & 48 hours & 45 minutes & 30 minutes & 55 minutes \\
\hline $4(J 2)$ & 3 hours and 45 minutes & 2 hours and 30 minutes & 1 hour and 45 minutes & 2 hours and 45 minutes \\
\hline
\end{tabular}

Delay $1 \mathrm{a}=$ Onset of complication and woman recognizes it

Delay $1 \mathrm{~b}=$ Complication is recognized, and woman seeks help

Delay $2 a=$ Woman leaves home and arrives to health centre

Delay $2 b=$ Woman is transferred from health centre to hospital

The probabilities of the perceived times occurring was between $15 \%$ and $80 \%$ in the case of the search for help (first delay) and between $40 \%$ and $80 \%$ in the case of the transfer (second delay) (Table 3); (Graph $1 \&$ 2). The mean values represented in the normal distribution curve graphs were similar to medians obtained. The highest probabilities of the perceived times occurring corresponded to J3 and J1, regarding the times invested in the search for help (80\%) and to J2, regarding the times invested in the transfer (80\%). Through the elicitation of probabilities from the jurisdictional physicians, the adjusted distribution curves for each of them were elaborated, as well as the curve corresponding to the four physicians obtained by consensus, for the first and second delays (Graph 3 \& 4).

Table 3: Probabilities of the perceived response times occurring in the care of pregnant women with obstetric emergency.

\begin{tabular}{|c|c|c|c|c|c|c|}
\hline \multirow{3}{*}{ Physician } & \multicolumn{3}{|c|}{ Search for help (First Delay) } & \multicolumn{3}{|c|}{ Transfer (Second Delay) } \\
\hline & \multirow{2}{*}{$\begin{array}{c}\text { Quartil } \\
\text { Lower }\end{array}$} & \multirow{2}{*}{ Median } & \multirow{2}{*}{$\begin{array}{l}\text { Quartil } \\
\text { Upper }\end{array}$} & \multirow{2}{*}{$\begin{array}{c}\text { Quartil } \\
\text { Lower }\end{array}$} & \multirow{2}{*}{ Median } & \multirow{2}{*}{$\begin{array}{l}\text { Quartil } \\
\text { Upper }\end{array}$} \\
\hline & & & & & & \\
\hline 1 (J1) & 0.6 & 0.7 & 0.8 & 0.4 & 0.5 & 0.6 \\
\hline $2(\mathrm{~J} 3)$ & 0.75 & 0.8 & 0.9 & 0.35 & 0.4 & 0.45 \\
\hline $3(\mathrm{~J} 2)$ & 0.12 & 0.15 & 0.17 & 0.65 & 0.8 & 0.85 \\
\hline $4(\mathrm{~J} 2)$ & 0.14 & 0.15 & 0.19 & 0.65 & 0.8 & 0.85 \\
\hline
\end{tabular}




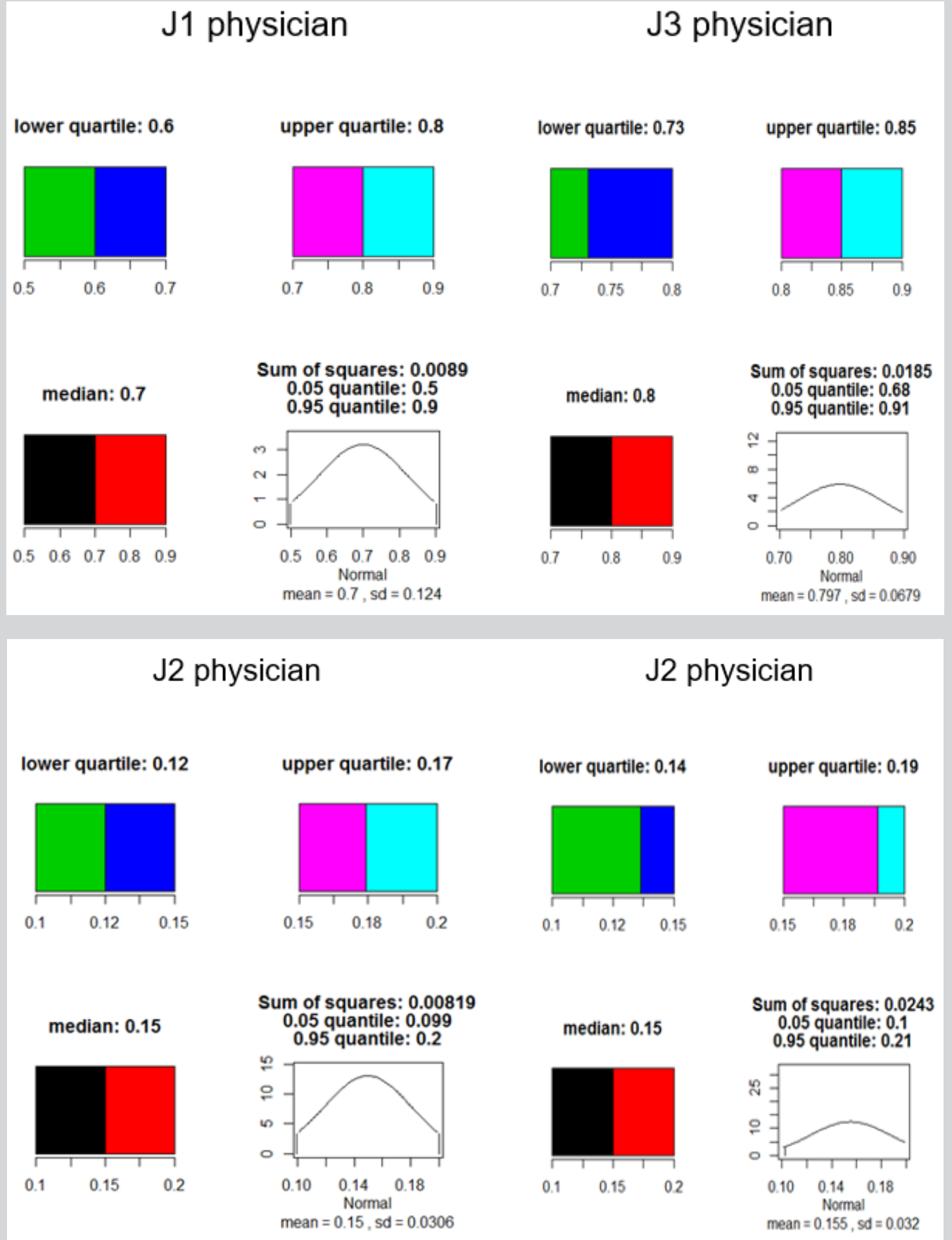

Graph 1: Median and their ranges of occurrence of response times perceived by physicians to the search for help of pregnant women with OEs (first delay). 


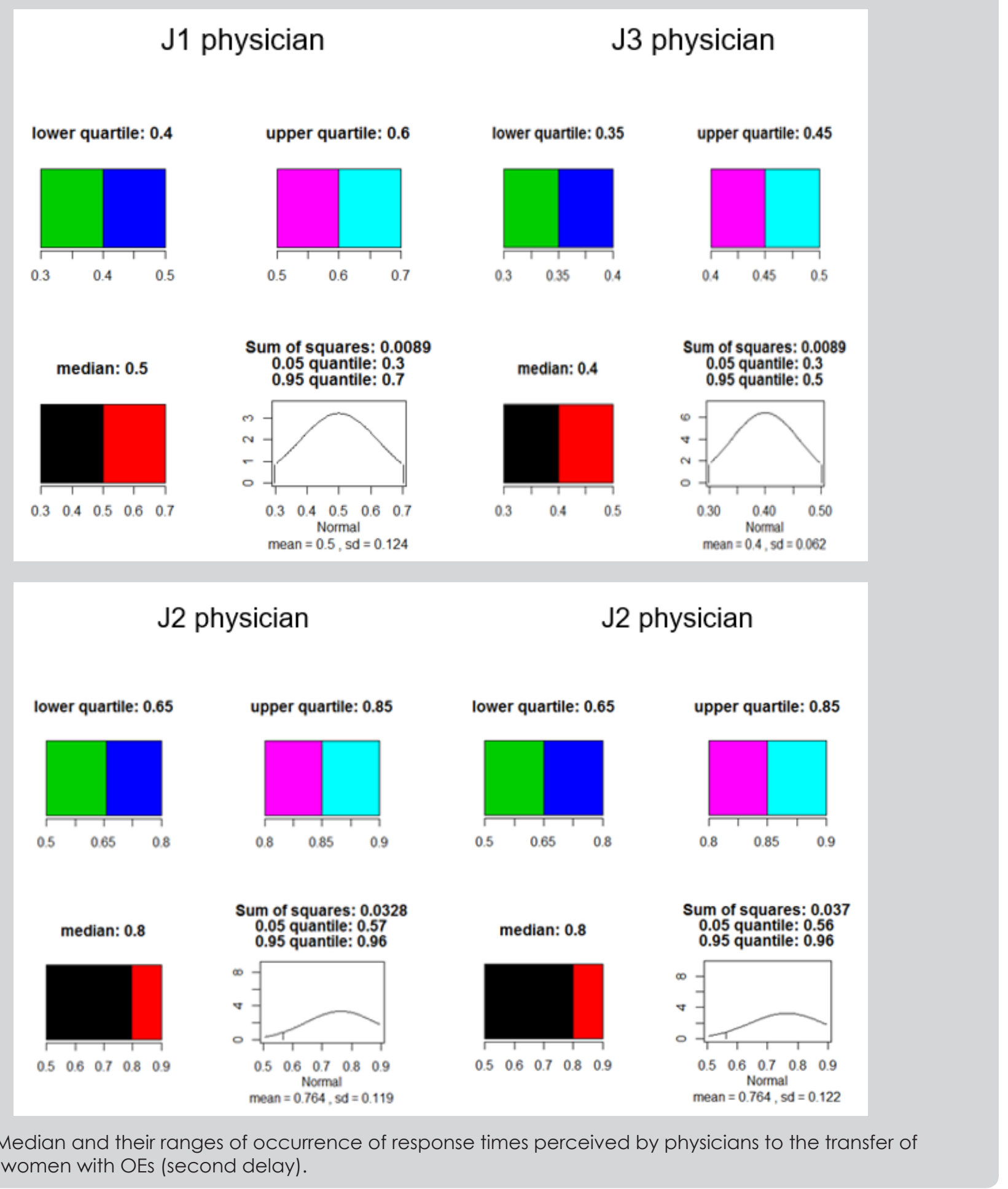




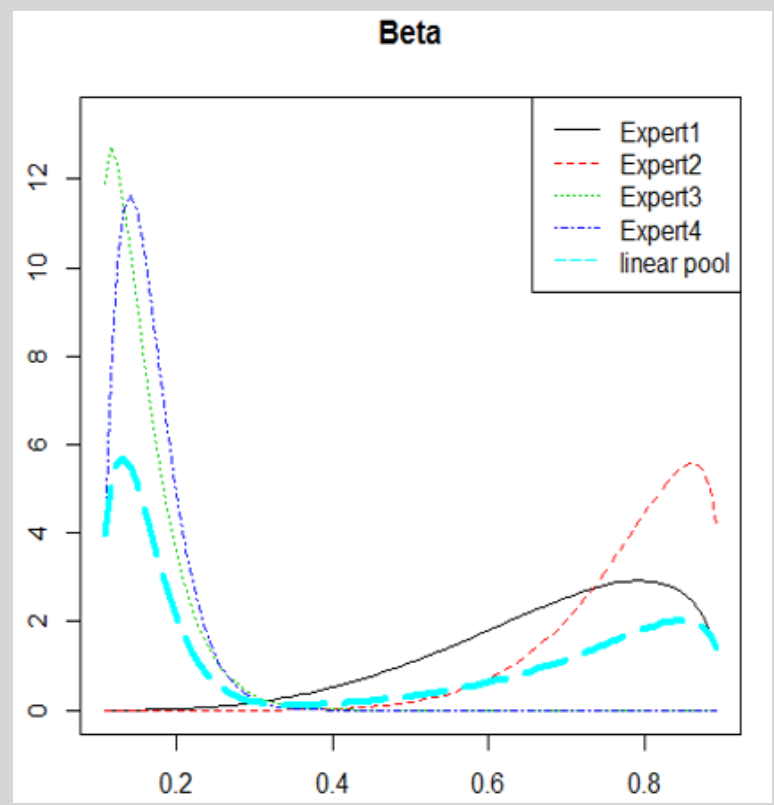

Graph 3: Adjusted individual and group probabilities (linear pool) of the physicians' perceptions and beliefs about the search for help (first delay) of pregnant woman with OEs.

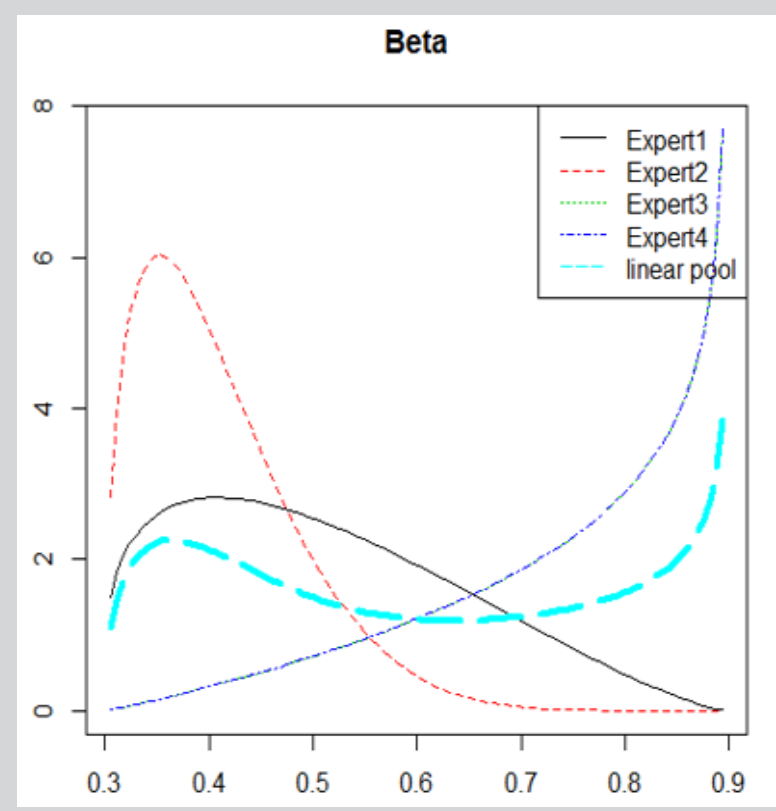

Graph 4: Adjusted individual and group probabilities (linear pool) of the physicians' perceptions and beliefs about the transfer (second delay) of pregnant women with OEs

\section{DISCUSSION}

Studies on the perceptions and beliefs of physicians about the response times of pregnant women in the sick for care of $\mathrm{OE}$ have been carried out regarding the second and third delays, but there are few that analyze the physicians' perceptions and beliefs in terms of the first delay. Considering the criteria established in this study of what is a time prolonged (1 hour or more), the OE care process was delayed in the three jurisdictions.

In this study, the probabilities that the perceived times were occurring during the process of seeking care for the pregnant woman to be attended for an OE in rural areas, were higher than the ones reported in a 2018 study with physicians from urban Yucatan:
$80 \%$ vs $39.1 \%$, respectively, for the first delay; and $80 \%$ vs $60.2 \%$, respectively, for the second delay [24].

In the present study, the response times in the care of an $\mathrm{OE}$ perceived by the physicians and corresponding to the first delay were related to the fact that the pregnant women did not become aware in time of the onset of the complication and delayed the decision to leave their house and search for help. At a community level, there is a need for information and education on the importance of immediate care for a maternal complication. Delay in care implies multiple causes: sociocultural, economic, political, gender- and access-to-services-related. When these concatenate, they maximize the risk of women postponing the time to be treated [25]. 
The elements that make up the community context have an impact on the health of pregnant women: habits, customs and reproductive risks are different from one culture to another [26,27]. This is why the programs and models aimed at preventing maternal deaths have to take into account the population's sociocultural traits, and they have to target mainly the needs of the rural areas $[28,29]$, which are different from those of the urban ones. In Yucatan, the perceived time for the first delay exceeded those reported for pregnant women in Rwanda, where women underwent between 12 and 24 hours of labor before being transferred and admitted into a hospital [30]. This shows the lack of timely care for obstetric complications at a community level. The time that women take to decide to search for help at this level also depends on the complication, as could be observed in the case of pre-eclamptic women in Haiti, whose median time was $13.4 \pm 30$ hours [31]. Time perceived by the J1 physician was also more prolonged than the one referred for Afghan women (30 days vs. 16.6 hours) when they suffered from an OE due to severe infection and were delayed in becoming aware of the complication. When they finally identified it, they were delayed in leaving their home to search for help (15 hours vs 4.1 hours) [32].

In terms of the perceived times regarding the occurrence of the second delay (transfer of the pregnant woman to a different level of care), the time that the women and their families take to get hold of a vehicle and a driver, in conjunction with their lack of economic resources to pay for the service, have been mentioned as the main barriers delaying the transfer to treat the emergency outside of their communities [17]. The lack of a vehicle when the emergency transfer is needed is the main barrier that has not been solved [33].

In the state of Yucatan, there are still communities where access is difficult due to lack of pavement on the roads, which prolongs the transfer time, even though, in some places, the municipal authority provides economic help towards this end. Moreover, the transfer vehicle is not at the Health Center; it is owned by the municipality and it is used for all types of transfers, not only OEs. The perceived times for the second delay, which range between two and a half hours to almost six hours, were similar to the times found by Hirose et al. [32] in 2015 among Afghan women with uterine rupture.

The transfer mechanisms of pregnant women in Yucatan were established more than 20 years ago during the health services regionalization process. There has not been another study that analyzes the present conditions regarding the territory and the demand for care and that takes into account the locality and the location of the second-level clinics where the women are transferred. Therefore, there is no updated local transferral instrument to inform the care guidelines for pregnant women with obstetric complications and to prevent delays regarding such care. This instrument should constitute a guideline including actions to prevent delays, based on population growth and the number of health centers and clinics; a permanent training program on the alarm signs-directed not only to the population, but also to the staff at the first level of care and a provision of material and equipment to treat the emergency. It has been shown that there are flaws in the diagnostic process and the administration of antibiotics in cases of sepsis where care was delayed [34]. In other countries, the health system has adopted a quality improvement approach to reduce the mortality of mothers and new-borns [35]. This is a future challenge for those in charge of the decision-making processes in the state of Yucatan. Only of these manners, the quality of care for pregnant women with OEs could be improved.
Likewise, the first level of prevention should be privileged to avoid, whenever possible, the occurrence of an obstetric complication. In the cases where it happens, the aim should be to reduce the response time in the care of pregnant women with OEs with mechanisms that are already in place according to the type of complication. These are challenges that should be faced and solved in the short run in Yucatan to contribute to the reduction of maternal and perinatal mortality. The continuous monitoring of pregnant women has been identified as a strategic factor in prevention, in conjunction with the implementation of mechanisms that reduce the response time for the treatment of pregnant women with OEs [36]. The high probabilities found and evidencing delays in the care of an $\mathrm{OE}$ in women who come from rural areas of Yucatan, require the attention of decision-makers who must propose strategies that reduce the time lost in recognize an obstetric complication and transfer to another hospital; to guarantee a safe delivery and contribute to the reduction of maternal mortality.

\section{CONCLUSION}

The prolonged response times in the treatment of OEs perceived by the physicians ranged between two and a half hours and 30 days, with a probability of occurrence between 15\% and $80 \%$ during the pregnant woman's search for help. Transfer times were also prolonged, ranging between one hour and 25 minutes and four and a half hours, with a probability of occurrence between $40 \%$ and $80 \%$. Therefore, strategies to reduce these times are needed. It is also necessary to strengthen activities of health promotion in the first level of care, among both the population and the local health staff. The transfer system of pregnant women should also be enhanced, so the delays in the response times are reduced and maternal and perinatal deaths prevented in Yucatan.

\section{REFERENCES}

1. United Nations (2018) Sustainable development goals report. New York, USA.

2. World Health Organization (2019) Maternal mortality. Key Facts. World Health Organization.

3. Moyer CA, Adongo PB, Aborigo RA, Hodgson A, Engmann CM, et al. (2014) "It's up to woman's people": How social factors influence facilitybased delivery in Rural Northern Ghana. Matern Child Health J 18: 109119.

4. (2015) World Health Organization, UNICEF, UNFPA, World Bank, United Nation Population Division. Trends in maternal mortality, 1990 to 2015. Geneva, USA.

5. Ouasmani F, Engeltjes B, Haddou RB, Belayachi O, Verhoeven C (2018) Knowledge of hypertensive disorders in pregnancy of Moroccan women in Morocco and in the Netherlands: a qualitative interview study. BMC Pregn Childb 18:344.

6. World Health Organization, UNFPA, UNICEF (2009) Averting maternal death and disability. monitoring emergency obstetric care. A handbook. Geneva, USA: 1-152.

7. Hirshberg A, Srinivas SK (2017) Epidemiology of maternal morbidity and mortality. Semin Perinatol 41(6): 332-337.

8. Assefa G, Laurence C, Adama Y, Misganaw A, Woldie S, et al. (2017) Trends and causes of maternal mortality in Ethiopia during 1990-2013: findings from the Global Burden of Diseases study 2013. BMC Public Health 17(1): 160.

9. Troiano N, Witcher P (2018) Maternal mortality and morbidity in the United States: Classification, causes, preventability and critical care obstetric implications. J Perinat Neonatal Nurs 32(3): 222-231.

10. The Partnership for Maternal Newborn \& Child Health (2011) Analysing 
commitments to advance the global strategy for women's and children's health. The PMNCH 2011 Report. Geneva, Switzerland: PMNCH.

11. Health (2020) Ministry of health United States of Mexico. General Director of Epidemiology. Weekly report of immediate notification of maternal death SINAVE: 1-6.

12. Thaddeus S, Maine D (1994) Too far too walk maternal mortality in context. Soc Sci Med 38: 1091-1110.

13. Rosado L, Rodríguez E, Andueza G (2008) Evaluation of the three delays model in maternal deaths in Yucatan. In: Ortega J, Guzman E (eds). Research and Health 3. Mexico: Autonomous University of Yucatan. Mérida, Yucatán, México. 325-339.

14. Rodríguez E, Aguilar P, Montero L, Hoil J, Andueza G (2012) Delays in the care of maternal complications associated with deaths in municipalities in southern Yucatan, Mexico. Rev Biomed 23: 23-32.

15. World Health Organization (2004) Making pregnancy safer: the critical role of the skilled attendant: a joint statement by WHO, ICM and FIGO. Geneva, USA.

16. World Health Organization (2018) Definition of skilled health personnel providing care during childbirth: the 2018 joint statement by who, UNFPA, UNICEF, ICM, ICN, FIGO and ipa. Geneva: World Health Organization.

17. Geleto A, Chojenta C, Musa A, Loxton D (2018) Barriers to access and utilization of emergency obstetric care at health facilities in sub-Saharan Africa: a systematic review of literature. Systematic Reviews 7-183.

18. Rodríguez Angulo E, Andueza Pech G, Oliva Peña Y (2018). Characteristics of maternal death among Mayan women in Yucatan, Mexico. Springer.

19. Rodríguez AE, Oliva PY, Andueza PG, Zapata VR (2017) Physicians' perceptions of the processes, barriers and strategies in the care of obstetric complications. J Womens Health Gyn 1-10.

20. Meyer M, Booker J (2001) Eliciting and analysing expert judgment. A practical guide. Society for industrial and applied mathematics. American statistical association. Academic Press Limited, Londres.

21. Federal government. United States of Mexico (2010) Quick reference guide. Detection and initial treatment of obstetric emergencies.

22. Gartawaite PH, Kadane JB, O’Hagan A (2005) A statistical method for eliciting probability distributions. J America Stats Assoc 100(470): 680701.

23. Oakley J (2016) Eliciting Probability distributions with shelf. The University of Sheffield, England.

24. Rodríguez-Angulo E, Pech GA, Vázquez RZ (2018) Global risk of death due to delays in the care of pregnant women with obstetric complication in Yucatan, Mexico. Obstet Gynecol Int J 9(2): 118-122.

25. Kalter H, Mohan P, Mishra A, Gaonkar N, Biswas A, et al. (2011) Maternal death inquiry and response in India-the impact of contextual factor on defining an optimal model to help meet critical maternal health policy objectives. Health Res Policy Syst 9: 41.

26. Lassi ZS, Middleton P, Bhutta ZA, Crowther C (2019) Health care seeking for maternal and newborn illnesses in low- and middle-income countries: a systematic review of observational and qualitative studies 8: 200 .

27. Adames H, Chavez-Dueñas N, Fuentes M, Salas S, Perez-Chavez J (2014). Integration of Latino/a cultural value into palliative health care: a culture centered model. Palliat Support Care 12(2): 149-157.

28. Republic of Argentina (2013) National Institute of Statistics and Census. National Survey on Sexual and Reproductive Health 2013 (ENSSyR 2013). Buenos Aires: INDEC; 2013.

29. Demaria L, Campero L, Vidler M, Walker D (2012) Non-physician providers of obstetric care in Mexico: Perspectives of physicians, obstetric nurses and professional midwives. Hum Resource Health 25(10): 6 .

30. Niyitegeka J, Nshimirimana G, Silverstein A, Odhiambo J, Lin Y, Nkurunziza T, et al. (2017) Longer travel time to district hospital worsens neonatal outcomes: a retrospective cross-sectional study of the effect of delays in receiving emergency cesarean section in Rwanda. BMC Pregn Childb 17: 242.

31. Hutchinson K, Bryant M, Bachman DeSilva M, Price D, Sabin, et al. (2018) Delayed access to emergency obstetrical care among preeclamptic and nonpreeclamptic women in Port-Au-Prince, Haiti. BMC Pregn Childb 18: 337.

32. Hirose A, Borchert M, Niksear H, Alkozai AS, Cox J, et al. (2011) Difficulties leaving home: a cross-sectional study of delays in seeking emergency obstetric care in Herat, Afghanistan. Soc Sci Med 73(7): 1003-1013.

33. Ehiri J, Alaofè H, Asaolu I, Chebet J, Esu E, et al. (2018) Emergency transportation interventions for reducing adverse pregnancy outcomes in low- and middle-income countries: a systematic review protocol. Syst $\operatorname{Rev} 7(1): 65$.

34. Seacrist MJ, Morton CH, VanOtterloo LR, Main EKJ (2019) Quality improvement opportunities identified through case review of pregnancy-related deaths from sepsis. Obstet Gynecol Neonatal Nurs 48(3): 311-320.

35. Sensalire S, Isabirye P, Karamagi E, Byabagambi J, Rahimzai M, et al. (2019) Saving mothers, giving life approach for strengthening health systems to reduce maternal and new-born deaths in 7 Scale-up districts in Northern Uganda. Glob Health Sci Pract 7 (Suppl 1): S168-S187.

36. Chalise B, Chalise M, Bista B, Pandey AR, Thapa S (2019) Correlates of continuum of maternal health services among Nepalese women: Evidence from Nepal multiple indicator cluster survey. PLoS One. 14(4): e0215613. 